\title{
Impacts of Climate Warming on Aviation Fuel Consumption
}

\author{
DIANDONG REN \\ School of Electrical Engineering, Computing and Mathematical Sciences, Curtin University, Perth, Australia, \\ and College of Oceanography, Hohai University, Nanjing, China \\ LANCE M. LESLIE \\ School of Mathematical and Physical Sciences, University of Technology Sydney, Sydney, Australia
}

(Manuscript received 10 January 2019, in final form 21 May 2019)

\begin{abstract}
Factors affecting aviation fuel efficiency are thermal and propulsive efficiencies, and overall drag on aircraft. An along-the-route integration is made for all direct flights in a baseline year, 2010, under current and future atmospheric conditions obtained from 26 climate models under the representative concentration pathway (RCP) 8.5 scenario. Thermal efficiency and propulsive efficiency are affected differently, with the former decreasing by $0.38 \%$ and the latter increasing by $0.35 \%$. Consequently, the overall engine efficiency decrease is merely $<0.02 \%$. Over the same period, the skin frictional drag increases $\sim 3.5 \%$ from the increased air viscosity. This component is only $5.7 \%$ of the total drag, and the $\sim 3.5 \%$ increase in air viscosity accounts for a $0.2 \%$ inefficiency in fuel consumption. A $t$ test is performed for the multiple-model ensemble mean time series of fuel efficiency decrease for two 20-yr periods centered on years 2010 and 2090, respectively. The trend is found to be statistically significant ( $p$ value $=0.0017$ ). The total decrease in aircraft fuel efficiency is equivalent to $\sim 0.68$ billion gallons of additional fuel annually, a qualitatively robust conclusion, but quantitatively there is a large interclimate model spread.
\end{abstract}

\section{Introduction}

Because commercial airliners consume massive amounts of fossil fuel (Figs. 1a,b), careful examination of the interactions between climate change and aviation is necessary. For example, the busy North Atlantic corridor (NAC) alone consumes $\sim \$ 4$ billion fuel annually (in 2010 U.S. dollars). Any fuel saved is an important contribution to reducing greenhouse gas (GHG) emissions and a more sustainable global environment. Climate warming involves the entire troposphere, covering essentially the cruising space of commercial airliners. For greater fuel efficiency, long-range flights always cruise near the tropopause, for the coldest temperature and the highest visibility. Other, particularly short-range, flights usually cruise at lower altitudes. Hence the effects of global warming on aviation are highly relevant.

The aviation effects (both $\mathrm{CO}_{2}$ and non- $\mathrm{CO}_{2}$ ) on climate, primarily through radiative effects of cirrus clouds formed from contrails, have been extensively

Corresponding author: Dr. Diandong Ren, rendianyun@ gmail.com investigated (e.g., Minnis et al. 1999; Sausen et al. 2005; Fichter et al. 2005; Stuber et al. 2006; Fu and Liou 1993). The Intergovernmental Panel on Climate Change (IPCC) special report, Aviation and the Global Atmosphere (Penner et al. 1999), summarized other aspects of the impact of aircraft on atmospheric properties. In contrast, climate effects on aviation (Williams and Joshi 2013; Ren et al. 2019) are not yet well investigated. For example, climate warming impacts on aviation fuel efficiency are of great economic value considering that $\sim 8 \times 10^{10}$ gallons of fuel are consumed annually by this sector of industry (e.g., http://www.transtats.bts.gov/ fuel.asp). The present lack of investigation of this topic primarily is because there are many cancelling effects, or many factors that balance each other, that make it difficult to draw definitive conclusions on the net effects. In particular, as a result of polar amplification, the mean strength of the midlatitude jets likely weakens (Ren 2010). The superimposed velocities from climate warming are persistent and not fluctuating on daily (airborne time of commercial flights) and shorter time scales. This will have significant effect on the drag (headwinds or tailwinds). However, for round-trip flights (e.g., all commercial airlines), the net effects are 


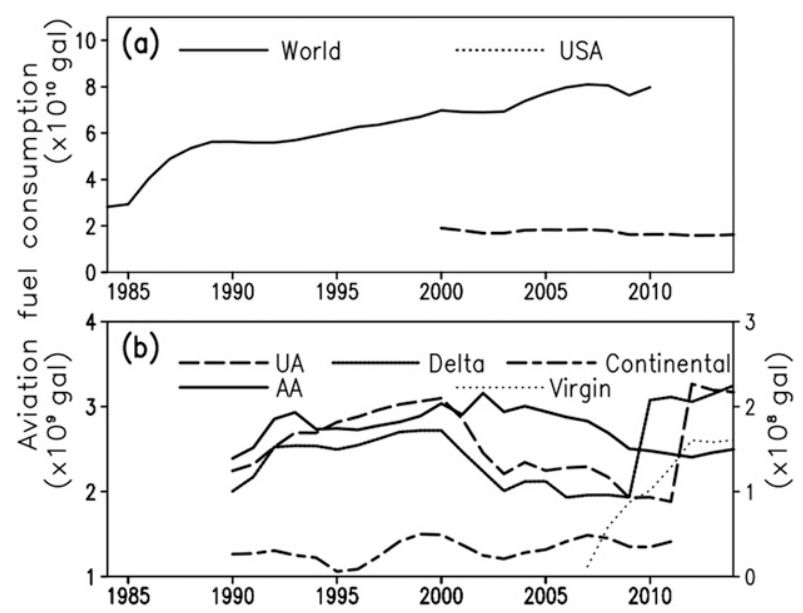

FIG. 1. Commercial aviation annual consumption of fuel (a) worldwide and for the United States (in $10^{10}$ gallons); and (b) the top 5 U.S. airlines (in $10^{9}$ gallons). More information for the domestic and international operations of the U.S. airlines can be found at http://www.transtats.bts.gov/fuel.asp. World-wide jet fuel consumption by year is available at http:/www.indexmundi.com/ energy.aspx? product $=$ jet-fuel\&graph $=$ consumption. Given that oil prices fluctuated greatly over the aviation era, the volume of fuel is used as a more stable index. With the fast increase from developing countries, the world total consumption has a steady trend of increase since 1985. The developed world, using the United States as an example, has a stable consumption but the absolute amount is considerable.

minuscule. For a high-quality routing scheme, such as that used operationally over the NAC, the weakened jets assist the efforts in minimizing head winds but are detrimental for attempts to maximize the harnessing of tail winds. Similarly, clear-air turbulence theoretically does not affect the total work needed to be done by the aircraft. Thus changes in turbulence as climate warms are not relevant for aviation fuel efficiency. In addition, thermal effects from increased ambient air temperature also tend to cancel each other for lift and induced drag.

In this study, we investigate two points that are relevant for aviation fuel efficiency: 1) the increase in air viscosity and 2) the decrease in overall engine efficiency with rising environmental air temperature. Because all aircraft effectively are air-chilled thermal engines, with increased ambient air temperature the engine efficiency decreases. With the increase in dynamic viscosity of air, which is a relatively small fraction of the total resistance, the skin friction increases. Increased air temperature also may increase the aircraft mechanical efficiency, as the cruising speed needs to be adjusted. The net effect on fuel efficiency will be examined here, using the proper knowledge of the tropospheric temperature changes, the geographical distribution and vertical stratification, and the details of the world's airline operations. Although the year 2005 is the separator for historical and scenario runs of climate models in phase 5 of the Coupled Model Intercomparison Project (CMIP5; Taylor et al. 2012), here the year 2010 is used as the reference period because 1) Earth's climate experienced gradual warming during 1970-2010; and 2) developing countries, especially China, experienced an aviation industry boom during this period well into the 2010s. If we use 2000 or $1970-80$ as the reference period, the factor of aviation industry growth cannot be excluded, thereby making it difficult to evaluate the climate change effects.

The largest uncertainty in the degree of warming resides with the industrial emission of GHGs and other pollutants in the atmosphere to which climate is sensitive, because modern climate has a clear footprint of human activity (IPCC 2001). The future state of the climate depends crucially on what emission controls nations choose to impose. Based on assumptions about driving forces such as patterns of economic and population growth, and technology development, emission scenarios (ESs) describe future release into the atmosphere of GHGs, aerosols, and other tracers. These ESs provide inputs to climate models. In the most recent IPCC assessment report (AR5; IPCC 2013), the driving scenario is in the form of representative concentration pathways (RCPs; Taylor et al. 2012). RCPs are a range of possible greenhouse gas concentration trajectories adopted by the IPCC. In this study, the climate model outputs assume the high greenhouse concentration RCP8.5 scenario (an RCP that leads to a radiative forcing of $8.5 \mathrm{~W} \mathrm{~m}^{-2}$ by year 2100). The lower concentration scenarios RCP4.5 and RCP6.0 are referenced when available.

Online commercial ticketing databases are browsed for available flights among global airports. Nondirect flights are decomposed to several "direct flights" in a row. An annual, global direct flight database is thus archived for this research. In reality, the effects of climate warming on aviation fuel consumption are highly complex, and a "line-by-line" adding method is used to estimate changes in fuel consumption. This article is organized as follows: In section 2, an approach to estimate aviation fuel efficiency is proposed, and the available data are reviewed. In section 3 , the results are presented, together with a detailed discussion. A summary is made in section 4 , including possible impacts of our results on the aviation industry and suggestions for future research.

\section{Data and methods}

Here we examine the energy required by an aircraft along its trajectory. It is also assumed that there are 
minimal changes in the takeoff and cruise speeds, and that associated changes in aircraft kinetic energy are negligible. The air density variation invoked requirements for changes in speeds are satisfied by adjusting attack angles and other mechanical parameters instead. The kinetic energy of the airplane generated by accelerating to takeoff speed, and then cruising speed, is not a negligible contributor to fuel cost and is precisely what makes airplane travel inefficient for short-distance journeys. Taking the payload to cruising altitude certainly requires work to overcome the gravitational field. In fact, a 1-km ascent almost equals the work needed for $30-80 \mathrm{~km}$ of horizontal cruising (estimated from normal fuel-burning rates at climbing and cruising stages of commercial aircraft, and the normal length of the climbing stage; in addition to the elevation-insensitive potential energy incremental rate, air density proportional resistance in the vertical direction is considered so that ascent at the higher altitudes is less fuel consuming). Future fluctuation in tropopause elevation (Santer et al. 2003; Reichler et al. 2003) might involve changing the cruising altitude of commercial airplanes. This is conditional on Federal Aviation Administration (FAA) regulations, and is not considered further. The remaining portion of the total work that needs to be done by an airplane en route is the product of the total drag (resistance) and the distance between the origin and destination. Whether fuel consumption can be reduced depends on how the total drag and overall engine efficiency are affected. In the following discussion, an imaginary airplane with fixed aerodynamic parameters (wing and fuselage geometry and size) and engine specifications is assumed. In calculating the total fuel usage, all these parameters are necessary. When discussing climate change effects on fuel efficiency, these airplane parameters are constant coefficients and are not shown in the expressions.

As aircraft engines are thermal engines, their thermal efficiency is adversely affected by environmental temperature rise. The second law of thermodynamics places a fundamental limit on the thermal efficiency $\left(\eta_{T}\right)$ :

$$
\eta_{T}=\varepsilon\left(1-T_{c} / T_{H}\right)
$$

where $\varepsilon$ is a technical limiting factor $(\sim 0.57)$ indicating actual engines' closeness to the ideal engine (Holman 1980), $T_{H}$ is the absolute temperature at which the heat enters the engine cycle [also called turbine entry temperatures (TETs)], and $T_{c}$ is the absolute temperature of the exhaust gases; $T_{c}$ closely follows the environmental air temperature $T_{a}$, with only a cooling technology-dependent constant difference. The efficiency of thermal engines increases with higher operating temperature and lower environmental temperature. There are active efforts in improving fuel burning and TETs during the past 50 years (section 7.4.1.2 of IPCC AR5, Aviation and the Global Atmosphere). In this study, for simplicity, it is assumed that both $T_{H}$ and $\varepsilon$ are not going to improve in the projection period (between 2010 and 2100). The $T_{c}$ is the only variable being considered varying along the cruising route. For all commercial brands in operation, the TETs published during 2010-14 are used. Except for several wellknown engine types, most engine companies are very protective of actual engine data and operating conditions, although there is much discussion in the literature and also information in places like the European Aviation Safety Agency (EASA) (and FAA) certificate (certificates for all of the engine types are publicly available), which has detailed listings of actual engine values in regions where engine measurements are made. The TETs can be deduced from the emission data. According to Eq. (1), decrease in thermal efficiency for common commercial engines, GE90, RB211, LAEV2500, and Lyulka, in response to a 1-K increase in environmental temperature $\left(T_{c}\right)$, are respectively $5.62 \times 10^{-4}, 5.88 \times 10^{-4}, 5.07 \times 10^{-4}$, and $4.94 \times 10^{-4}$. The effects on engine thermal efficiency from climate change are transferred to the air temperature variations along the flying routes (legs). As the airplane moves forward by ejecting exhaust backward, how the kinetic energy (extracted from the fuel-burning chemical energy) is partitioned among aircraft and exhaust jet (i.e., used for pushing aircraft forward versus removed by the exhaust) is measured by the mechanical (propulsive) efficiency $\left(\eta_{M}\right)$ :

$$
\eta_{M}=\frac{2}{1+V_{e} / V_{a}}
$$

where $V_{e}$ is effective exhaust speed (jet speed relative to airplane), and the airplane speed $V_{a}$ is relative to the ground. The $\eta_{M}$ reaches maximum when the jet exhaust is stationary relative to the ground (all extracted energy from fuel burning is used to push the aircraft forward). Here exhaust speed is retrieved from TETs and engine pressure ratios (Cumpsty 1997). Equation (2) is derived in the inertial frame coordinates based on energy and momentum conservation. The commercial passenger aircraft generally have effective jet speeds $V_{e}$ within the range of $600-850 \mathrm{~m} \mathrm{~s}^{-1}$. The lower the effective jet speed (i.e., close to the cruising speed), the more sensitive the mechanical efficiency is to airplane cruising speeds. Overall efficiency $\eta$ is the product of mechanical efficiency and thermal efficiency (i.e., $\eta=\eta_{M} \times \eta_{T}$ ). 
Factors lowering (enhancing) overall efficiency result in higher (lower) fuel cost.

While it is apparent that drag is proportional to fuel cost, the picture for how total drag is affected by climate change is more complicated, because of the multiple sources involved. Classifying the many drag terms into pressure drag (e.g., induced drag, wave drag, and form drag) and skin friction drag is convenient because the pressure drags tend to be proportionally affected by air temperature and density changes. For example, for a specific design, the effects from environmental air on induced drag and net lift are usually proportional. Thus, the changes in skin friction are decisive for the sign of the extra drag on top of total drag stress. To separate out climate change effects on aviation, it is assumed here that there is no technological advance in design of subsonic aircraft used for commercial airlines during the time span under consideration:

$$
F_{d}=\iint_{S}\left(p-p^{*}\right) \hat{\mathbf{n}} \hat{i} d A+\iint_{S} \tau \hat{\mathbf{t}} \hat{i} d A,
$$

where $F_{d}$ is total drag, $\hat{\mathbf{n}}$ and $\hat{\mathbf{t}}$ are, respectively, unit vectors in the direction perpendicular and parallel to the local surface element $(d A), p$ is pressure, $\tau$ is skin friction drag, and $\hat{i}$ is the flow (drag) direction. For a specific type of airplane, the second term on the right-hand side of Eq. (3) can be parameterized as $p^{*} S c_{1} R_{e}^{c_{2}}$, where $S$ is wing area and $R_{e}$ is Reynolds number. Coefficients $c_{1}$ ( $\sim 0.074$ for well-painted, undented surfaces) and $c_{2}$ $(\sim-0.2)$ are aircraft dependent. Apparently, the drag coefficient is inversely related with the Reynolds number. Increased flow speed tends to increase $R_{e}$ while increased temperature, with consequently increased dynamic viscosity, tends to reduce $R_{e}$. Without resorting to strict model calculation, it is difficult to estimate accurately the net effect from climate warming to total drag. Also, for the same payload (cruise-level lift), $\rho\left|\mathbf{V}_{a}\right|^{2}$ is assumed to be an invariant entity (reference pressure $p^{*}$ ). For example, as air warms up, the air density $\rho$ decreases, with the same payload (and thus the same lift), takeoff and cruise speeds $\left|\mathbf{V}_{a}\right|$ need to increase. This results in an increase in propulsive efficiency $\left[\eta_{M}\right.$ in Eq. (2)] and hence is a contribution to the overall efficiency.

To estimate the total annual fuel consumption, a line-by-line adding method is used that considers all available (in operation as of 2010) commercial airlines and their scheduled flights. The integration is along the flying trajectory. There are many kinds of alliances and partnerships between the various commercial airlines. A trip involving multiple stops is likely to be carried out by different airlines in collaboration. For example, between Beijing and Singapore, there are 14 companies offering a subweekly frequency transportation service. Asiana and Air China, for example, have a service first to Seoul then to Singapore. Cathay Pacific and Thai Airlines stop, respectively, at Hong Kong and Bangkok. Xiamen Airlines makes two stops between Beijing and Singapore (Beijing $\rightarrow$ Zhoushan $\rightarrow$ Xiamen $\rightarrow$ Singapore). To eliminate possible recounting of the legs, only direct flights (each involves one takeoff, cruise and one landing) between airports are analyzed. In the above case between Beijing and Singapore, there are just five such daily flights, from Air China (A975 and A976, Airbus 330s) and Singapore Airlines (SA801, 805, Boeing 777s as carrier, and SA 807, an Airbus 380-800 as carrier). Connecting flights from the same airline or several partner airlines are considered to be several connected direct flights, with distinct flight profile legs and usually carried out using different types of aircraft. All such "direct flights" involve a normal seven-stage, A-G, flight profile. These are as follows: A: start and taxi to runway; B: takeoff and initial climbing; $\mathrm{C}$ : climbing to cruising altitude; D: en route cruising; E: descent; F: approach [includes $\sim 8$-min holding at $\sim 1500 \mathrm{ft}(\sim 457 \mathrm{~m})$, approach and landing]; and G: taxi to docking. For example, the Xiamen Airline schedule from Beijing to Singapore is looked upon as a direct flight from Beijing to Zhoushan, followed by a direct flight from Zhoushan to Xiamen, and another direct flight from Xiamen to Singapore. In this case, the same types of aircraft are used. However, for intercontinental flights, usually different types of aircraft are involved and the intercontinental legs cruise at a higher altitude than the domestic legs. For example, currently from Perth, Western Australia, to Austin, Texas, the leg of the flight from Sydney to Los Angeles uses A380, which cruises at $\sim 13-\mathrm{km}$ altitude $(\sim 200 \mathrm{hPa})$, while the aircraft used from Perth to Sydney is an A220, which cruises at a lower altitude of $\sim 7 \mathrm{~km}$. The connecting flight from Los Angeles to Austin is an MD-80, which cruises at an altitude of $\sim 9-10 \mathrm{~km}$.

To piece together annual flights between global airports, two commercial air-ticketing databases are searched. Information about airlines and their carrier aircraft is obtained. It then is a simple task to identify what types of engines are installed on those airplanes, because airlines (e.g., China Southern) have their fleet description publicly available. Some exceptions also are taken into consideration. For example, although Boeing manufactures the Dreamliner, it is the customer (airlines) who decide which engine is installed. In this case, Boeing selected both GE and Rolls-Royce to build the plane's engine options, to reduce the time and cost of engine changes if necessitated (e.g., when 
TABLE 1. Twenty-six climate models (GCMs) used in this study.

\begin{tabular}{|c|c|c|}
\hline Model name & Institution & Horizontal resolution \\
\hline ACCESS1-0 & CSIRO/Bureau of Meteorology & $192 \times 145$ \\
\hline ACCESS1-3 & CSIRO/Bureau of Meteorology & $192 \times 145$ \\
\hline CanESM2 & Canadian Centre for Climate Modelling and Analysis & $128 \times 64$ \\
\hline CNRM-CM5 & Centre National de Recherches Météorologiques & $256 \times 128$ \\
\hline CCSM4 & National Center for Atmospheric Research & $288 \times 192$ \\
\hline CESM1-BGC & National Center for Atmospheric Research & $288 \times 192$ \\
\hline CESM1-CAM5 & National Center for Atmospheric Research & $288 \times 192$ \\
\hline CSIRO-Mk3.6.0 & Commonwealth Scientific and Industrial Research Organisation (CSIRO) & $192 \times 96$ \\
\hline FGOALS-g2 & Institute of Atmospheric Physics, Chinese Academy of Sciences & $128 \times 60$ \\
\hline GFDL-CM3 & Geophysical Fluid Dynamics Laboratory & $144 \times 90$ \\
\hline GFDL-ESM-2G & Geophysical Fluid Dynamics Laboratory & $144 \times 90$ \\
\hline GFDL-ESM-2M & Geophysical Fluid Dynamics Laboratory & $144 \times 90$ \\
\hline GISS-E2-H & NASA Goddard Institute for Space Studies (GISS) & $144 \times 90$ \\
\hline GISS-E2-R & NASA GISS & $144 \times 90$ \\
\hline HadGEM2_AO & $\begin{array}{l}\text { National Institute of Meteorological Research, Korea Meteorological Administration } \\
\text { (South Korea) }\end{array}$ & $192 \times 145$ \\
\hline HadGEM2_CC & Met Office Hadley Centre & $192 \times 145$ \\
\hline HadGEM2_ES & Met Office Hadley Centre & $192 \times 145$ \\
\hline IPSL-CM5A-LR & L'Institut Pierre-Simon Laplace (France) & $96 \times 96$ \\
\hline IPSL-CM5A-MR & L'Institut Pierre-Simon Laplace (France) & $144 \times 143$ \\
\hline IPSL-CM5B-LR & L’Institut Pierre-Simon Laplace (France) & $96 \times 96$ \\
\hline MIROC5 & Atmosphere and Ocean Research Institute, The University of Tokyo & $256 \times 128$ \\
\hline MRI-CGCM3 & Meteorological Research Institute & $320 \times 160$ \\
\hline MPI-ESM-LR & Max Plank Institute (MPI) for Meteorology & $128 \times 64$ \\
\hline MPI-ESM-MR & Max Plank Institute (MPI) for Meteorology & $192 \times 96$ \\
\hline NorESM1-M & Bjerknes Centre for Climate Research, Norwegian Meteorological Institute & $144 \times 96$ \\
\hline NorESM1-ME & Bjerknes Centre for Climate Research, Norwegian Meteorological Institute & $144 \times 96$ global grids \\
\hline
\end{tabular}

one type of engine has issues raised during an upgrade, or simply for improving fuel-burning efficiency and leaving a smaller carbon footprint). If a flight involves transfers, it is decomposed into several connected individual flight legs, as exemplified by the Beijing to Singapore case described above.

Estimating the fuel efficiency change by the end of the twenty-first century requires atmospheric parameters (i.e., air temperature and humidity) from multiple climate models (all under the same RCP8.5 scenario) to drive expressions [Eqs. (1)-(3)], weighted by airplanespecific aerodynamic parameters. Ensemble averages are taken after the along trajectory integrations driven respectively by all climate models (Table 1 ). The climate model outputs are obtained from the IPCC Deutsches Klimareshenzentrum (DKRZ) Data Distribution Centre (http://www.ipcc-data.org/sim/gcm_monthly/ AR5/Reference-Archive.html). For models providing multiple perturbation runs, only r1i1p1 runs are used. The designator, r1i1p1, simply identifies the ensemble model runs. It is composed of three two-character terms indicating the model run (r1), initial conditions (i1), and model physics ( $\mathrm{p} 1$ ) employed. So, for the ensemble model climate projections, r1i1p1, all ensemble members use the same initial conditions and the same physical parameterizations.

\section{Results and discussion}

Earth's climate is accepted as warming, as reflected in the global expansion of pressure level geopotential heights over the past 50 years. Figure 2 shows the observed changes of $500-\mathrm{hPa}$ geopotential heights (in decameters, or $10 \mathrm{~m}$ ) between the periods $1960-85$ and 1985-2010, during the austral summer. The area encompassed by the $585-\mathrm{dm}$ line more than doubled, increased from covering $7.4 \times 10^{7}$ to $18.2 \times 10^{7} \mathrm{~km}^{2}$. The expansion of the isolines of geopotential height is a global phenomenon and indicates a lifted center of mass of Earth's atmosphere.

In addition, the recent salient increase in tropopause height heralds the effects of climate change on aviation. Figure 3 is the CCSM projected increase of tropopause height and tropopause air temperature changes between two 20-yr periods centered respectively on 1990 and 2090. Tropopause increase is a global phenomenon. The signal over the busy NAC is especially noticeable (at a rate $>1 \mathrm{~m} \mathrm{yr}^{-1}$ ). Tropopause temperature also has an increasing trend, but generally is within $1 \mathrm{~K}$ century ${ }^{-1}$. Other GCMs give similar responses (figures not shown, for brevity). The pronounced increase of tropopause height as a result of anthropogenically forced climate change is a robust, first-order response of the climate 
$500 h P a$ Geopotential Heights (10m) (Austral Summer: Nov-Feb)

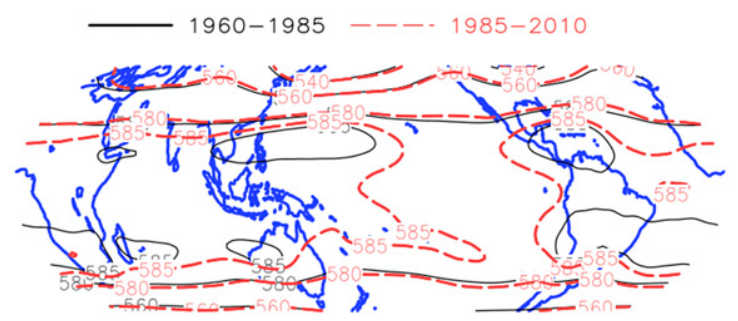

FIG. 2. The signatures of climate warming during the past 50 years: changes of 500-hPa geopotential heights (in decameter, or $10 \mathrm{~m}$ ) for austral summer. Mollweide projection is used so the areal proportionality is preserved. For example, the 585 dam line has expanded poleward significantly during the past 50 years (more than doubled, increased from covering an area of $7.4 \times 10^{7}$ to $18.2 \times 10^{7} \mathrm{~km}^{2}$ ). The expansion of the isolines of geopotential height is a global phenomenon and indicates a lifted center of mass of the Earth's atmosphere. Geopotential height data were obtained from monthly NCEP-NCAR reanalysis (http://www.esrl.noaa.gov/ $\mathrm{psd} / \mathrm{data} /$ gridded/data.ncep.reanalysis.html).

system to forcing by well-mixed GHGs and stratospheric ozone depletion (Santer et al. 2003; Lorenz and DeWeaver 2007).

In the estimation of fuel efficiency change by the end of the twenty-first century, the temperature changes for all vertical levels between 850 and $50 \mathrm{hPa}$ estimated from 26 CGCMs (Table 1 ) are used. These 26 models are chosen primarily because they are from distinct/independent modeling centers and provide all the required atmospheric fields required for our integration schemes. They are selected in this study also because the authors have accumulated experience with the systematic bias of the models from previous studies (e.g., Ren and Leslie 2015; Ren 2010). During the twentieth-century historical runs, their time series of geopotential heights (mass field), specific humidity (vapor content), and air temperatures (internal energy) all have systematic biases but the trends satisfactorily represent reality, compared with NCEP-NCAR reanalysis, for polar (Ren et al. 2011) as well as lowerlatitude regions (Ren and Leslie 2015). The analysis approach adopted in this study determines that the changes in atmospheric fields, rather than its climatological mean, are important for estimating the changes in fuel efficiency. In this sense, the intermodel spread of their base states (e.g., regional extremes can reach $3 \mathrm{~K}$ for air temperature, $2.7 \mathrm{~g} \mathrm{~kg}^{-1}$ for near-surface specific humidity, and $150 \mathrm{~m}$ for 5880-m geopotential heights) are less important. At present, it still is unrealistic to expect climate models to agree with reality on a day-to-day basis. However, for an arbitrary 20-yr running mean centered on any year between 1900 and 2100, the horizontal spatial patterns are similar among the 26 models at all model levels encompassing the commercial aviation space.
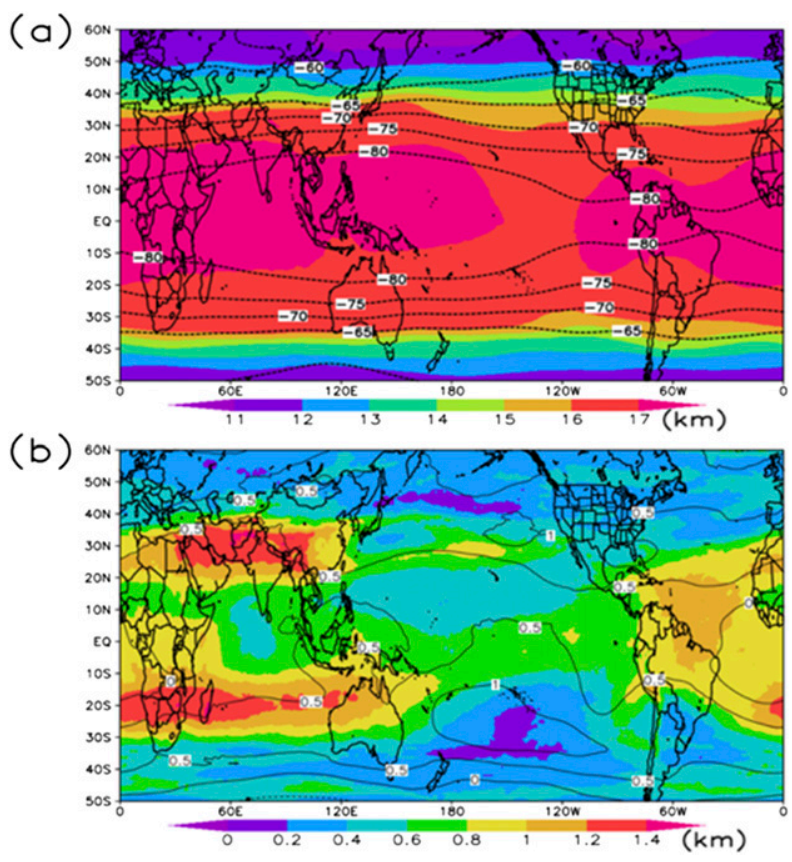

FIG. 3. (a) CCSM4 simulated tropopause height (shades) and tropopause temperature (contour lines) during a control period (1980-2000). (b) The projected differences between (2080-2100) and the control period, under the RCP8.5 emission scenario, are shown. The increases in tropopause height are a global phenomenon. For most regions, tropopause temperatures also increase.

It is assumed that the current airline routes and the aircraft used to carry out the flights do not change during this period (e.g., after 2010). This assumption is necessary because the air temperature warming is nonuniform spatially (geographically and vertically in the stratified atmosphere). Different types of aircraft or the same type of aircraft traveling different routes (long range vs short range) may cruise at very different altitudes and thus experience different changes in environmental conditions. Analyses carried out here are company by company, aircraft by aircraft, and for each scheduled flight in the year 2010. For each flight, an integration along the aircraft trajectory, from takeoff to landing, is made to estimate the engine efficiency and drag work under a current climate and the expected warmer climate in 2100. The differences in work required are converted to equivalent aviation fuel amounts. The along-trajectory integration is rotated for all 26 climate models under the RCP8.5 scenario. The ensemble average is taken among the fuel amounts consumed respectively from being driven by the 26 climate models. The same processes are adopted for estimating the drag changes between current and future climate, except that specific humidity and air temperature both are involved.

Although a high level of consensus was achieved among these sophisticated climate models in their 


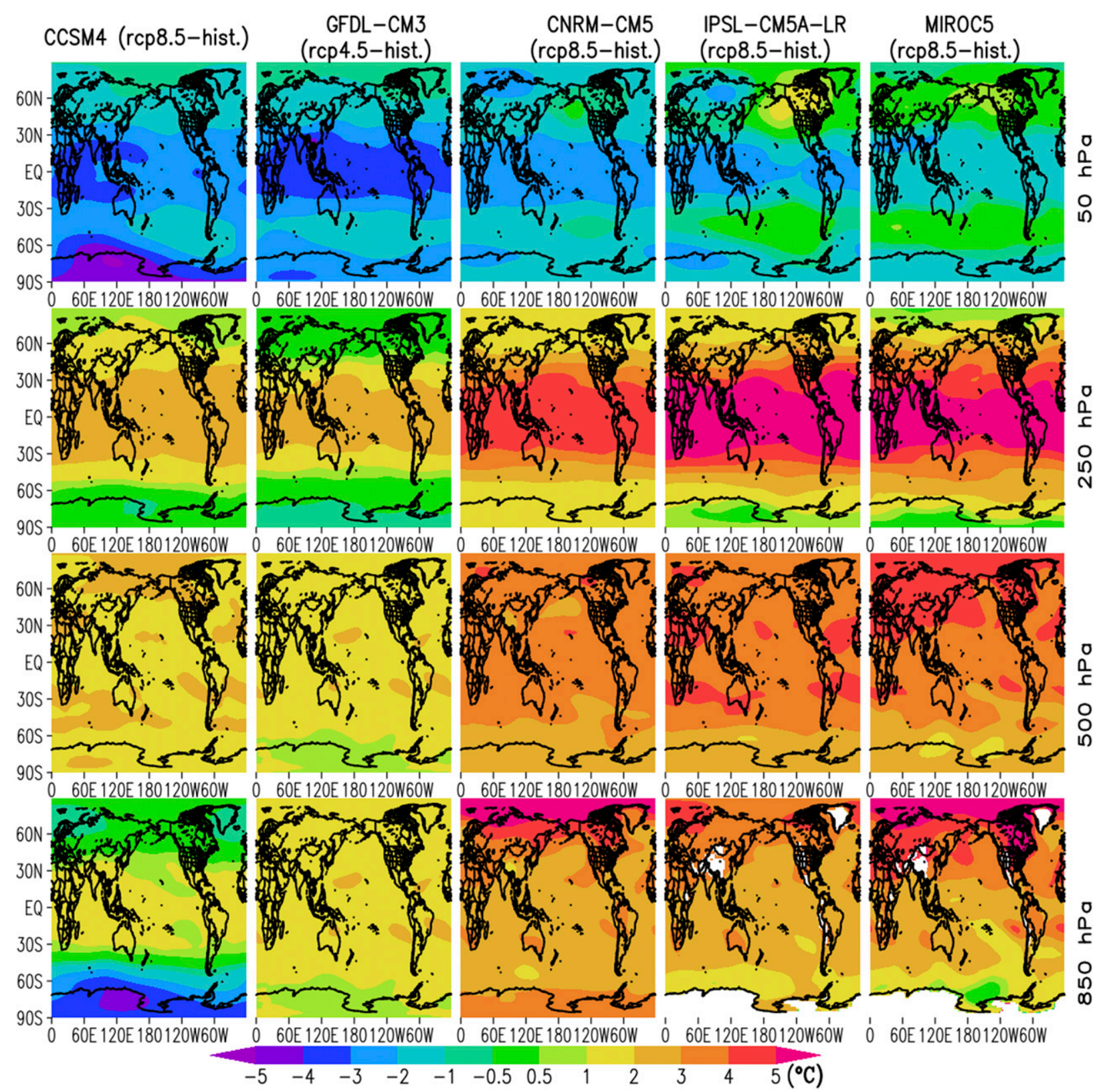

FIG. 4. Sophisticated modern climate models have a consensus on the vertical nonuniformity of climate warming. Climate model predicted 100-yr warming [K, annual mean (2050-2100 under RCP8.5, except GFDLCM2, which is under RCP4.5) minus 1950-2000 historical runs] in four vertical levels encompassing the civil aviation flying tracks $(850,500,250,50 \mathrm{hPa}$, from bottom to top). Below $250 \mathrm{hPa}$, warming is a global phenomenon, even though quantitatively there are large regional discrepancies among climate models. Above the tropopause zone $(200-50 \mathrm{hPa})$, which is the typical long-range flights cruising level, there can be significant polar, cooling regions.

simulations of the rise in average global temperatures, they have variable skill in simulating regional details and vertical profiles (Fig. 4). For example, MIROC (hires) $\left(1.2^{\circ}\right.$ horizontal resolution $)$ and IPSL-CM5 $\left(\sim 3.75^{\circ}\right.$ horizontal resolution) are of very different horizontal resolution but show very similar spatial pattern of warming at the four selected levels, and also at the other vertical levels (not shown). The first singular vector obtained from the singular vector decomposition (SVD; Wallace et al. 1992) indicated that the temporal correlation coefficient between the monthly temperatures is as high as 0.65 . Regional details and vertical profiles of temperature are important for examining their effects on aviation. The most important requirement (for simulations to approximate reality) is an adequately fine spatial resolution. Figure 4 shows the projected 100 -yr warming 
(K), that is, the 2050-2100 minus 1950-2000 (from historical runs) annual mean temperature, from five climate models at four vertical levels $(850,500,250$, $50 \mathrm{hPa}$ ), under the RCP8.5 scenario. Below $250 \mathrm{hPa}$, warming is a global phenomenon, even though quantitatively there are some large regional discrepancies among the climate models. Above $200 \mathrm{hPa}$, the typical cruising ceiling of long-range flights, significant polar cooling regions are indicated by the models. In particular, over the NAC, the elevated tropopause (which is between 200 and $50 \mathrm{hPa}$, the upper portion of the elevated tropopause) is colder in 2100 because of a cooling trend in the stratosphere (Santer et al. 2003; Ramaswamy et al. 1996).

Changes in fuel efficiency can be estimated from the 26 climate models by integrating, along all the direct flight routes, the thermal efficiency [Eq. (1)], mechanical efficiency [Eq. (2)] and the overall stress equations [Eq. (3)] under current and future atmospheric conditions. As different engines have different TETs and compression ratios, their responses to a warming environmental temperature are very different. Examination of the drag terms indicates that pressure drag and lift are proportionally affected by atmospheric warming. Under the assumption here of the same payload and same aircraft design, pressure drags are not affected by climate warming and only skin friction is relevant. Figures $5 \mathrm{a}-\mathrm{c}$ illustrate the overall responses of thermal efficiency, propulsive efficiency and skin friction, respectively, as the climate warms along the routes. The changes are shown as percentages, compared with year 2010 level $\left(\eta_{T 0}, \eta_{M 0}\right.$, $\left.\tau_{0}\right)$, in a relative sense. As expected, the thermal efficiency will gradually be reduced at a rate of about $3 \times$ $10^{-5} \mathrm{yr}^{-1}$. That is, by the year 2100 , the thermal efficiency will be reduced by $0.38 \%$ (again compared with the efficiency around year 2010, $\Delta \eta_{T}=0.0038$ ). When an aircraft cruises in a less dense atmosphere, the required cruising speed must increase proportionally. As a direct consequence, the propulsive efficiency decreases. For the global airlines as a whole, propulsive efficiency decreases are of similar magnitudes to the decreases in thermal efficiency. By year 2100, the changes in mechanical efficiency are about $0.35 \%\left(\Delta \eta_{M}=0.0035\right)$. The net reduction in overall engine efficiency thus is $\left(\eta_{M}+\right.$ $\left.\Delta \eta_{M}\right)\left(\eta_{T}+\Delta \eta_{T}\right)-\eta_{M} \eta_{T} \approx 0.0001543$ for current technology. That is, from just an engine efficiency point of view, there is a reduction of less than $0.02 \%$.

For the same payload (cruise-level lift), $\rho\left|\mathbf{V}_{a}\right|^{2}$ is assumed to be an invariant entity (reference pressure $\left.p^{*}\right)$. For example, as air warms up, the air density $\rho$ decreases, with the same payload (and thus the same lift), takeoff and cruise speeds $\left|\mathbf{V}_{a}\right|$ need to increase.
This results in an increase in propulsive efficiency $\left[\eta_{M}\right.$ in Eq. (2)], and hence is a contribution to the overall efficiency. On the other hand, if air density (at the same altitude) has increased, for aircraft to maintain the same speed, the effective exhaust speed needs to increase and results in a decrease in mechanical efficiency. Because the cruising altitude is assumed unchanged, the latter (density effect) is close to reality and the decrease in propulsive efficiency, taking the global airlines as a whole, is of similar magnitudes to the decrease in thermal efficiency. By the year 2100, the changes in mechanical efficiency are expected to be about $0.35 \%$, and, consequently, the net reduction in overall engine efficiency is $\sim 0.7 \%$ for current technology. That is, from just an engine efficiency point of view, there is slightly less than a $1 \%$ reduction of fuel efficiency.

The percentage change in skin friction drag is caused primarily by the increased kinematic viscosity of air, within the cruising space, which has a temperature lapse rate of about $8 \times 10^{-8} \mathrm{~m}^{2} \mathrm{~s}^{-1} \mathrm{~K}^{-1}$. Figure $5 \mathrm{c}$ indicates that, for all operating airlines considered, there could be a $3.5 \%$ increase in skin frictional drag by 2100 $\left(\Delta \tau / \tau_{0}=0.035\right)$, whereas the skin friction drag is only $\sim 5.7 \%$ of the total drag. The increase in skin frictional drag accounts only for a $\sim 0.2 \%$ reduction in efficiency in fuel consumption. Thus, because of increased air viscosity and decreased engine overall efficiency, the annual fuel consumption in 2100 would be $\sim 0.9 \%$ higher than around 2010 (Fig. 5d). The spread of the estimations is wide among climate models (e.g., the standard deviations of the 26 climate models range from $0.07 \%$ to $0.35 \%$ for thermal efficiency, $0.06 \%$ to $0.3 \%$ for mechanical, and $0.06 \%$ to $0.15 \%$ for skin friction drag) but all indicate greater fuel consumption as climate warms. The corresponding absolute change of a $0.9 \%$ reduction in efficiency in fuel consumption is considerable, about 0.68 billion gallons of fuel annually. The reduction in thermal efficiency is complementary to the IPCC AR5 perspective, but the fact that the increased drag and mechanical efficiency may be a new concept and hopefully will stimulate further studies. A $t$ test is performed for the overall decrease of fuel efficiency time series (the thick red line in Fig. 5d). For two 20-yr periods centered on years 2010 and 2090, a $p$ value of 0.0017 (degrees of freedom $=38$ ) is obtained. At this significance level, it means at a possibility of $99.84 \%$ the trend is not mere coincidence. Thus, the net decrease of fuel efficiency is small but nevertheless is statistically significant.

\section{Discussion and conclusions}

It is clear that both innovation in emission controls and advances in aviation technology can reduce fuel 


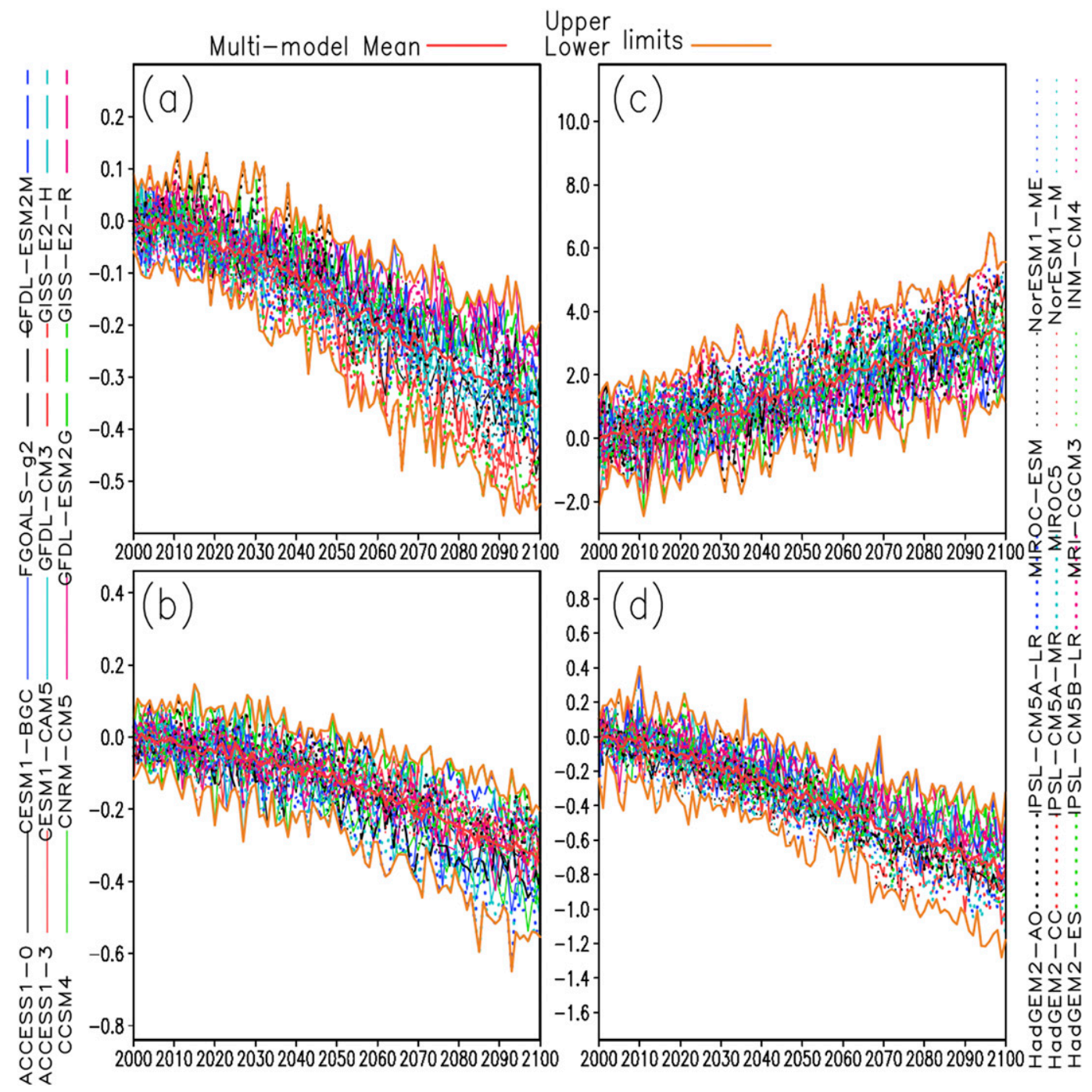

FIG. 5. Decreases in (a) thermal efficiency and (b) mechanical efficiency, (c) increase in skin frictional drag, and (d) the overall decrease in fuel efficiency during 2000-2100, for the entire commercial aviation sector as a whole. Multiple climate model ensemble mean (shown as thick red lines) and the ranges of the variability (thick yellow lines) are shown for 24 climate models under RCP8.5 emission scenarios (for clarity only, the other two models both lie within the range). The flight schedules of year 2010 are assumed unchanged during the entire period. Note that the control period is centered on 2010 (2005-15), so the values at starting (2000) are not exactly unity.

consumption. Therefore, the analyses presented here might be an overestimation. For example, the reduction in engine thermal efficiency will not hold if the TETs continue to increase, as indicated in IPCC AR5. This may result in a net increase in overall engine efficiency. For long, intercontinental distances, aircraft travel remains the most energy-efficient option.

It is noted that this study could, instead, be an underestimate of fuel consumption for at least two reasons. First, the tropopause fluctuations could mean a higher cruising altitude in the future. The increased potential energy of the airplane, according to the current rate of tropopause increase $\left(\sim 0.3 \mathrm{~m} \mathrm{yr}^{-1}\right)$, would still be an order of magnitude smaller than the factors considered here (only $\sim 0.004 \%$ of the total fuel cost). This, however, seems to be a steady effect. Second, we did not consider the impact of severe weather on flight tracks in the 3D space. The expected increase in severe weather events in a warming climate (Pendergrass 2018; Dey et al. 2019) also would contribute to additional fuel costs. Because fuel cost is the primary cost for the airlines, all of the above factors require further investigation.

Given that currently there is no access to the airlines flight logs, the normal seven-stage flight (A-G) profiles were used. All stages are sensitive to a warming environment in terms of fuel-burning efficiency. The cruising 
speeds can be derived from flight schedule information. Fuel burn rates are engine specific, and the requirements of the various engines were considered along the idealized flight profile. The estimates obtained in this study certainly can be further refined in upcoming studies, particularly if actual flight logs become publicly available. However, the greatest uncertainty in our estimates still lies in the emissions scenario. Exact numbers presented here should not be taken too literally. Notably, the climate models have large spreads in the values of all terms considered here, with $t$ tests indicating that all 26 models have statistically significant trends. Consequently, the finding that warming has adverse effects on aviation fuel costs is a robust conclusion.

Fuel costs are the principal expenditures for the civil aviation industry, especially for long-range international flights, and the cruising stage is by far the largest portion of the total cost. Accordingly, the fuel saving aspect of aircraft design is primary. However, an overemphasis on fuel efficiency in aircraft design can raise safety issues. Hence, this study suggests that a less warm global climate, achievable, for example, by meeting the RCP4.5 emissions, or even a stricter scenario target, arguably is the best means of reducing aviation fuel consumption.

Acknowledgments. The original idea for this research came from the postdoctoral research RD carried out with Prof. David Karoly in 2005. We thank Dr. Y. Li (then in CSIRO) and Dr. J. Li (BNU) and Professors Zhaomin Wang (Hohai University) and W. Guo (Nanjing University) for discussions on aspects of climate change and the consequences for societal and economic issues. We also thank H. Thiemann for technical assistance in obtaining the IPCC AR5 data from the Deutsches Klimareshenzentrum (DKRZ) website. Finally, we express our gratitude to anonymous reviewers for excellent reviews that greatly improved the text. This study is supported by a 6-month contract (2018) to the first author, through Fundamental Research Funds (2019B03114) granted to College of Oceanography, Hohai University.

\section{REFERENCES}

Cumpsty, N. A., 1997: Jet Propulsion. Cambridge University Press, 363 pp.

Dey, R., S. Lewis, J. Arblaster, and N. Abram, 2019: A review of past and projected changes in Australia's rainfall. Wiley Interdiscip. Rev.: Climate Change, 10, e00577, https://doi.org/10.1002/ wcc.577.

Fichter, C., S. Marquart, R. Sausen, and D. Lee, 2005: The impact of cruise altitude on contrails and related radiative forcing. Meteor. Z., 14, 563-572, https://doi.org/10.1127/0941-2948/2005/0048.

Fu, Q., and K. Liou, 1993: Parameterization of the radiative properties of cirrus clouds. J. Atmos. Sci., 50, 2008-2025, https://doi.org/ 10.1175/1520-0469(1993)050<2008:POTRPO>2.0.CO;2.
Holman, J., 1980: Thermodynamics. McGraw-Hill, 217 pp.

IPCC, 2001: Climate Change 2001: The Scientific Basis. Cambridge University Press, $881 \mathrm{pp}$.

- 2013: Climate Change 2013: The Physical Science Basis. Cambridge University Press, 1535 pp., https://doi.org/10.1017/ CBO9781107415324.

Lorenz, D., and E. DeWeaver, 2007: Tropopause height and zonal wind response to global warming in the IPCC scenario integrations. J. Geophys. Res., 112, D10119, https://doi.org/10.1029/ 2006JD008087.

Minnis, P., U. Schumann, D. Doelling, K. Gierens, and D. Fahey, 1999: Global distribution of contrail radiative forcing. Geophys. Res. Lett., 26, 1853-1856, https://doi.org/ 10.1029/1999GL900358.

Pendergrass, A., 2018: What precipitation is extreme? Science, 360, 1072-1073, https://doi.org/10.1126/science.aat1871.

Penner, J., D. Lister, D. Griggs, D. Dokken, and M. McFarland, Eds., 1999: Summary for policy makers. Aviation and the Global Atmosphere, Cambridge University Press, 373 pp., https://www.ipcc.ch/site/assets/uploads/2018/03/av-en-1.pdf.

Ramaswamy, V., M. Schwarzkopf, and W. Randel, 1996: Fingerprint of ozone depletion in the spatial and temporal pattern of recent lower stratospheric cooling. Nature, 382, 616-618, https://doi.org/10.1038/382616a0.

Reichler, T., D. Martin, and R. Sausen, 2003: Determining the tropopause height from gridded data. Geophys. Res. Lett., 30 , 2042, https://doi.org/10.1029/2003GL018240.

Ren, D., 2010: Effects of global warming on wind energy availability. J. Renewable Sustainable Energy, 2, 052301, https:// doi.org/10.1063/1.3486072.

_ , and L. M. Leslie, 2015: Changes in tropical cyclone activity over Northwest Western Australia in the past 50 years and a view of the future 50 years. Earth Interact., 19, https://doi.org/ 10.1175/EI-D-14-0006.1.

_ R. Fu, L. M. Leslie, J. Chen, C. Wilson, and D. Karoly, 2011: The Greenland ice sheet response to transient climate change. J. Climate, 24, 3469-3483, https://doi.org/10.1175/2011JCLI3708.1.

_ , R. E. Dickinson, R. Fu, J. F. Bornman, W. Guo, S. Yang, and L. M. Leslie, 2019: Impacts of climate warming on maximum aviation payloads. Climate Dyn., 52, 1711-1721, https://doi.org/ 10.1007/s00382-018-4399-5.

Santer, B., and Coauthors, 2003: Behavior of tropopause height and atmospheric temperature in models, reanalyses, and observations: Decadal changes. J. Geophys. Res., 108, 4002, https://doi.org/10.1029/2002JD002258.

Sausen, R., and Coauthors, 2005: Aviation radiative forcing in 2000: An update on IPCC (1999). Meteor. Z., 14, 555-561, https://doi.org/10.1127/0941-2948/2005/0049.

Stuber, N., P. Forster, G. Radel, and K. Shine, 2006: The importance of the diurnal and annual cycle of air traffic for contrail radiative forcing. Nature, 441, 864-867, https://doi.org/10.1038/ nature 04877 .

Taylor, K., R. Stouffer, and G. Meehl, 2012: An overview of CMIP5 and the experiment design. Bull. Amer. Meteor. Soc., 93, 485-498, https://doi.org/10.1175/BAMS-D-11-00094.1.

Wallace, J., C. Smith, and C. Bretherton, 1992: Singular value decomposition of wintertime sea surface temperature and $500-\mathrm{mb}$ height anomalies. J. Climate, 5, 561-576, https://doi.org/10.1175/ 1520-0442(1992)005<0561:SVDOWS >2.0.CO;2.

Williams, P., and M. Joshi, 2013: Intensification of winter transatlantic aviation turbulence in response to climate change. Nat. Climate Change, 3, 644-648, https://doi.org/10.1038/ nclimate1866. 